\title{
Can Osteoprotegerin be a Target of Therapy in Type 2 Diabetes Mellitus?
}

\section{Alexander E Berezin*}

Internal Medicine Department, State Medical University, Zaporozhye, Ukraine

\begin{abstract}
Osteoprotegerin (OPG) is a soluble member of the tumor necrosis factor receptor superfamily, which exhibits the close link to Cardiovascular (CV) disease in Type 2 Diabetes Mellitus (T2DM). Recent clinical studies have been shown that elevated OPG might be a marker of vascular calcification / remodeling and CV events and CV mortality in T2DM without known CV disease. However, it remains unclear whether OPG would be a target for therapy of diabetics with antidiabetic drugs and statins. The aim of the mini review: to summarize knowledge with respect to OPG utilization as predictor of CV adverse effects and as a target of therapy in T2DM. The review is discussed the evidence regarding possibility to prevent microvascular and macrovascular complications in diabetics through control of OPG level as a target in therapy. Although there are not irresistible findings that the post-treatment OPG level in diabetics and CV events might be related, possibility to use OPG for risk stratification of vascular remodeling / ectopic calcification and CV-related mortality in T2DM appears to be attractive. The future investigations are needed to explain whether serum OPG would be informative for biomarker-guided therapy in T2DM individuals.
\end{abstract}

Keywords: Diabetes mellitus; Osteoprotegerin; Cardiovascular events; Target therapy; Prediction

\section{Abbreviations}

ApoE: Apolipoprotein E; CV: Cardiovascular; DPP-4: Dipeptidyl Peptidase 4; GLP-1: Glucagon-Like Peptide-1; GLUT1: Glucose Transporter-1; HbAlc: Glycated Hemoglobin; hs-CRP: HighSensitive C-Reactive Protein; IL: Interleukin; LV: Left Ventricular; OPG: Osteoprotegerin; RANKL: Receptor Activator of Nuclear factor-Kappa B Ligand; SMCs: Smooth Muscle Cells; T2DM: Type 2 Diabetes Mellitus; TNF: Tumor Necrosis Factor; TRAIL: TNF-Related Apoptosis-Inducing Ligand

\section{Introduction}

Type 2 Diabetes Mellitus (T2DM) is a serious global health burden with increasing prevalence predominantly in the developing countries [1]. Development and progression of T2DM closely associate with microvascular and macrovascular complications negatively affected all cause and Cardiovascular (CV) mortality rates [2,3]. However, contemporary treatment approaches based on improved glycemic control have been exhibited an ability to contribute in decreased CV complications related to T2DM, whereas utilization of modern strategy is higher cost and appears to be economic challenge to the health care system [4-6]. In this context, several circulating biomarkers represented differential metabolic profiles, related to vascular complications and predicted $\mathrm{CV}$ events may be clinically helpful for risk stratification and individualized treatment for T2DM patients $[7,8]$. Although various biomarkers (natriuretic peptides, galectin-3, soluble ST2, growthdifferentiation factor-15, signature of microRNAs, oxidative stress components, inflammatory cytokines, biomarkers of coagulation and endothelial damage) are widely used as predictors of adverse clinical outcomes in several settings [9-12], there is concern regarding their role as biological target in T2DM care $[8,13]$.

Osteoprotegerin (OPG) is a secretory glycoprotein that belongs to the Tumor Necrosis Factor (TNF) receptor family and involves in the regulation of bone metabolism, ectopic calcification including vascular calcification processes, vascular tone enhance and endothelium regeneration [14]. Elevated level of OPG has found in CV disease patients, individuals with asymptomatic atherosclerosis, hypertension, T2DM, metabolic syndrome, chronic renal disease, and malignancy [14-18]. However, evidence regarding OPG may be causative for CV events in T2DM patients appears to be controversial [19-21] and requires more investigations. The aim of the review: to summarize knowledge with respect to OPG utilization as predictor of CV adverse effects and as a target of therapy in T2DM.

\section{Biological Role of OPG}

OPG (also known as Tumor Necrosis Factor [TNF]-SF11B) is a soluble decoy receptor for the Receptor Activator of Nuclear factorKappa B Ligand (RANKL) shown to be a key regulator of osteoclast differentiation and bone remodeling [22]. This effect is related to an ability of OPG to inhibit the expression of bone resorption activators Receptor Activator of Nuclear factor Kappa B Ligand (RANKL) on surface of the target cells [23]. It has been suggested that $1 \alpha$, 25-dihydroxyvitamin D3 is able to promote the secretion of OPG by osteoblasts and prevents osteopenia of bones [23], while similar assumption has not been confirmed in the clinical studies [24,25]. Overall, expression of OPG was found at the surface of wide spectrum of cells. Therefore, several cells distinguishing osteoblasts, i.e., active mononuclears, macrophages, T-cells, endothelial cells, bone-marrow progenitor cells may produce and secrete OPG due to cytokines' stimulation [26]. In this context, overproduced OPG is considered as a marker of inflammatory activation with various biological effects on target cells [27].

\section{The Role of OPG in Vascular Remodeling and Diabetes}

OPG has been hypothesized to modulate vascular remodeling and functions. As a suppressor of TNF-Related Apoptosis-Inducing Ligand (TRAIL), OPG negatively affects matrix metalloproteinase-9 activity in smooth muscle cells (SMCs) in the media of arterial wall and it prevents

*Corresponding author: Alexander E Berezin, Professor, Consultant of Therapeutic Unit, Internal Medicine Department, State Medical University, Zaporozhye, Ukraine, Tel: +380612894585; E-mail: dr_berezin@mail.ru

Received March 09, 2016; Accepted March 31, 2016; Published April 05, 2016

Citation: Berezin AE (2016) Can Osteoprotegerin be a Target of Therapy in Type 2 Diabetes Mellitus? Metabolomics 6: 172. doi:10.4172/2153-0769.1000172

Copyright: (c) 2016 Berezin AE. This is an open-access article distributed under the terms of the Creative Commons Attribution License, which permits unrestricted use, distribution, and reproduction in any medium, provided the original author and source are credited. 
the chemo-attractive effect mediating TRAIL on SMCs [28]. As a result, TRAIL-related effects on death receptor-4 and death receptor 5 are inhibited and cell survival is increased [29]. Interestingly, among T2DM subjects OPG has associated with reduced parasympathetic function and exhibited a neuroprotective capability [30]. Additionally, OPG seems to exert proatherogenic and prodiabetogenic effects via pro-inflammatory capability mediating insulin resistance [31,32]. Furthermore, OPG may promote beta cell dysfunction directly and through the upregulation of the local renin-angiotensin system activity [33]. In dysmetabolic individuals (diabetics, obese, metabolic syndrome individuals) serum OPG correlated positively with $\mathrm{HbA1c}$, adiponectin, leptin, high-sensitive C-reactive protein (hs-CRP), and RANKL levels, as well as negatively with leptin [34]. Although adipose tissue and bone tissue can influence glucose metabolism, potentiality in insulin-dependent manner, OPG seems to be a conductor of interplaying both tissues. Indeed, Glucose Transporter-1 (GLUT1) expression on osteoblasts has not altered, and insulin did not reverse most of the effects of glucose [35]. In this context, OPG might mediate capability of osteoblasts glucose uptake [36]. Finally, OPG attenuates vascular wall thickness, vascular remodeling, restores endothelial function, prevents arterial calcification and neuropathy, and stabilizes plaque formation $[30,36,37]$.

\section{OPG and CV Outcomes}

Elevated level of circulating OPG was found in general population at higher risk of T2DM, dysmetabolic individuals including T2DM beyond $\mathrm{CV}$ disease and in patients with known CV and renal disease. Data of epidemiological and prospective studies have indicated that in patients with known CV disease elevated serum OPG levels are associated with several inflammatory markers (hs-CRP, TNF, interleukins), arterial stiffness, as well as atherosclerosis (based on plaque determination and calcium scores), stable angina and myocardial infarction, acute and chronic heart failure [20,21,38-40]. Modulating vascular stiffness and ectopic calcification OPG plays a pivotal role in vascular remodeling and endothelial dysfunction that are considered a clue of CV disease development and progression. In this context, OPG was found as a powerful marker of microvascular and macrovascular complications [41], while a causality role of OPG with respect to both settings are not completely defined. However, there is no confided evidence that OPG would be factor of tissue damage. Contrary, elevated OPG is rather protector from ectopic calcification and progressive remodeling that might be utilized for risk stratification among general patients' population and T2DM individuals with $\mathrm{CV}$ disease beyond classic $\mathrm{CV}$ risk factors [42]. Moreover, there are results of the clinical trials elucidated that elevated serum levels of OPG predicted CV outcomes including death in subjects with known CV disease and T2DM [4244]. Therefore, serum OPG may be a marker for the severity of diabetic nephropathy [45]. Whether is link between elevated OPG as a marker of vascular calcification / remodeling and CV events and CV mortality in T2DM without known CV disease still remains unanswered $[46,47]$.

\section{The Role of OPG Gene Polymorphisms in Diabetes- Related Vascular Complications}

Contributing of OPG in CV disease and events among T2DM population might mediate via OPG gene polymorphisms. Based on previous animal investigations it has found that OPG knockout associated with increased bone resorption, arterial calcification and osteoporosis [16,47]. The OPG deficient mice (OPG -/- mice) showed a higher systolic blood pressure, larger Left Ventricular (LV) chamber and reduced wall thickness than did age-matched wild type mice, as well as a greater heart weight / body weight ratio [48]. Apolipoprotein E (Apo E)-KO mice with loss of the OPG gene has exhibited reduced ability to formation of angiotensin II-induced aneurysm [49].

Clinical studies haven't reported controversial results regarding predictive relevance of OPG polymorphism. Soysal-Atile et al. [50] reported that the A163G polymorphism of the OPG gene was not associated with microvascular or macrovascular complications of T2DM. Contrary, Duan et al. [51] presented data regarding the associations of 21 single-nucleotide polymorphisms in OPG gene with elevated diastolic blood pressure. Yet, T245G, T950C, and G1181C gene polymorphisms of the OPG gene were related to the development of peripheral arterial occlusive disease and critical limb ischemia in T2DM individuals [52]. Mankoč et al. [53] have shown that polymorphisms of the OPG genes rs2073618 (located in exon I) and rs3134069 (located in the promoter region) might relate to diabetic retinopathy in Slovenian patients with T2DM. Finally, OPG gene may be implicated in the pathogenesis of target organs damage in T2DM, while the predictive value of polymorphisms in OPG gene requires more investigations.

\section{The Effect of Antidiabetic Drugs on OPG and Vascular Remodeling}

It remains unclear whether treatments for T2DM are capable of promoting or inhibiting vascular remodeling and ectopic calcification. There is evidence regarding an ability of exogenous insulin to downregulate OPG in vitro and in vivo and attenuate vascular calcification [53]. Although insulin may reduce an expression of OPG / RANKL in vasculature in a dose- and time-dependent manner, the role of exogenous insulin in long-term control for development and progression of tissue damage appears to be controversial [54] and it requires more investigations. This controversial investigation appears to be unclear effect of insulin on calcified cells. On the one hand, insulin may induce ectopic calcification [54]. On the other hand, acute hyperinsulinemia is able to decrease plasma level of OPG in T2DM [55]. Whether increased levels of OPG in arteries' wall and plasma in T2DM subjects would be predicted CV risk related to the hyperinsulinemia is not fully clear [55].

Pre-clinical and clinical studies have been shown that novel classes of antidiabetic drugs, i.e., Glucagon-Like Peptide (GLP)-1 receptor agonist and dipeptidyl peptidase 4 (DPP-4) inhibitors GLP-1 can directly and functionally interact with osteoblastic cells, possibly through a GPI / IPG-coupled receptor [56,57]. Interestingly, that GLP-1 receptor agonist liraglutide and probably DPP-4 inhibitors might not exert osteogenic effects in diabetic states. Is this effect class specifically or not it is not unclear. By now, in animal model short administration of GLP-1 receptor agonist exenatide leaded to be increase osteocalcin gene expression and the OPG / RANKL ratio - at the expense of an augmented OPG-above corresponding control values in the tibia $[58,59]$. However, there is no evidence regarding novel GLP-1 receptor agonists such as taspoglutide and albiglutide on OPG-mediated vascular calcification and vascular remodeling. Overall, GLP-1 receptor agonists may probably reverse the bone alterations and attenuate ectopic calcification via OPG-depended pathways.

The effect of thiazoledinediones on circulating OPG is controversial. Nybo et al. [60] reported that rosiglitazone among patients with T2DM reduces the plasma level of OPG. Esteghamati et al. [61] have been compared the anti-inflammatory properties of pioglitazone and metformin with respect to their effect on serum concentrations of OPG newly diagnosed T2DM. Authors reported that 
both drugs leaded to be comparable effect on decreased serum OPG. Park et al. [62] have revealed that pioglitazone in T2DM individuals decreased OPG and hs-CRP levels, whereas in metformin group biomarkers' levels were unchanged. Unfortunately investigators did not assay vascular calcification / remodeling in the study. Koufany et al. [63] in animal model has confirmed that pioglitazone might reduce serum level of RANKL and OPG, decreased the level of inflammatory bone destruction and protected the bone microarchitecture. However, there is evidence that Interleukin (IL)-17 / RANKL-dependent ectopic calcification could be controlled by pioglitazone via inhibition of retinoic acid receptor-related orphan nuclear receptor $\gamma t$ and activation of peroxisome proliferator-activated receptor $\gamma$. Whether these findings would be clinically relevant is not still clear. Further studies are needed to determine the effect of thiazoledinediones on bone formation, ectopic calcification and vascular remodeling.

Theoretically, metformin may act as an inhibitor of OPG / RANKL / RANK system, while final result of metformin on bone metabolism, ectopic calcification and vascular remodeling might be variable. Metformin attenuated the suppression on proliferation with increased expression of Col I, OCN, and OPG, meanwhile suppressing metal matrix proteinases 1 and 2 [64]. Overall, metformin has attenuated the suppression effect of high glucose to the osteoblast proliferation and gene expression, more prominently in earlier stage of T2DM [65]. On the other hand, metformin has been exhibited suppressive effect on bone resorption possibly by lowering the RANKL / OPG ratio and reducing the number of osteoclasts [66].

The role of sulphonylurea antidiabetic drugs in OPG controlling is uncertain [67] and requires explanation.

\section{Impact of Statins on OPG Level}

Statins are widely used in the patients with T2DM aimed to treat dyslipidemia, reduces vascular inflammation, and prevent $\mathrm{CV}$ events / CV mortality / all-cause mortality. T2DM patients with coronary artery disease / atherosclerosis showed derangements in serum levels of all vascular calcification inhibitors compared with those in healthy controls. The results of clinical studies have reported controversial effect of statins on OPG level. Usually, T2DM patients with known asymptomatic and symptomatic atherosclerosis on statin therapy had reduced serum RANKL / OPG ratio, as compared to untreated patients [68]. Short-term atorvastatin and simvastatin treatment significantly decreased serum OPG level $[69,70]$. Contrary, fluvastatin administration could increase the OPG levels and attenuate vascular calcification [71]. Importantly, that statins may attenuate the progenitor cell mobilization from bone marrow via RANKL-induced stimulation of cell proliferation, which is enhanced through OPG expression [72]. Rationality to use of statin aimed restore endothelium integrity and function through OPG / RANKL activation pathway in progenitor cells is widely discussed [73]. However, the role of statins in the bonevascular axis is unknown and the clinical relevance of these findings requires further investigation.

\section{Conclusion}

Anti-diabetic drugs and statins might be uncertain effect on OPG level in T2DM patients. There is not irresistible evidence regarding possibility to use OPG as a target in therapy of diabetes. However, the future investigations are needed to explain whether serum OPG would be informative for biomarker-guided therapy in T2DM individuals with and without known CV disease.

\section{References}

1. Guariguata L, Whiting DR, Hambleton I, Beagley J, Linnenkamp U, et al. (2014) Global estimates of diabetes prevalence for 2013 and projections for 2035 Diabetes Res Clin Pract 103: 137-149.

2. Straka RJ, Liu LZ, Girase PS, DeLorenzo A, Chapman RH (2009) Incremental cardiovascular costs and resource use associated with diabetes: an assessment of 29,863 patients in the US managed-care setting. Cardiovasc Diabetol 8: 53.

3. Wu WX, Ren M, Cheng H, LiY, Qi YQ et al. (2014) Prevention of macrovascular disease in patients with short-duration type 2 diabetes by multifactorial target control: an 8 year prospective study. Endocrine 47: 485-92.

4. Jacob L, Waehlert L, Kostev K (2016) Changes in Type 2 Diabetes Mellitus Patients in German Primary Care Prior to (2006) and After $(2010,2014)$ Launch of New Drugs. J Diabetes Sci Technol 10: 414-420.

5. Grabner M, Peng X, Geremakis C, Bae J (2015) Demographic and Clinical Profiles of Type 2 Diabetes Mellitus Patients Initiating Canagliflozin Versus DPP-4 Inhibitors in a Large U.S. Managed Care Population. J Manag Care Spec Pharm 21: 1204-12.

6. Menzin J, Korn JR, Cohen J, Lobo F, Zhang B, et al. (2010) Relationship between glycemic control and diabetes-related hospital costs in patients with type 1 or type 2 diabetes mellitus. J Manag Care Pharm 16: 264-275.

7. Berezin $A E$ (2015) Cardiovascular biomarkers in routine screening of diabetic patients. Clinical and Medical Biochemistry 1: 107-112.

8. Berezin AE (2015) The Role of Cardiac Biomarkers in Predicting of Mortality in Diabetic Patients. Journal of Cardiol Ther 5: 273-278.

9. Wang C, Wan S, Yang T, Niu D, Zhang A, et al. (2016) Increased serum microRNAs are closely associated with the presence of microvascular complications in type 2 diabetes mellitus. Sci Rep 6: 20032

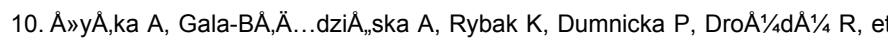
al. (2015) Role of new biomarkers for the diagnosis of nephropathy associated with diabetes type 2. Folia Med Cracov 55: 21-33.

11. Domingueti CP, Dusse LM, Carvalho MD, de Sousa LP, Gomes KB, et al (2015) Diabetes mellitus: The linkage between oxidative stress, inflammation, hypercoagulability and vascular complications. J Diabetes Complications.

12. Berezin A (2015) Diabetes mellitus related biomarker: the predictive role of growth-differentiation factor-15. Diabetes and Metabolic Syndrome: Clinical Research and Reviews.

13. Berezin A (2016) Is rationale to decrease serum osteoprotegerin and fetuin-A in type 2 diabetes mellitus patients? Diabetes Metab Syndr.

14. Pérez de Ciriza C, Lawrie A, Varo N (2015) Osteoprotegerin in Cardiometabolic Disorders. Int J Endocrinol 2015: 564934

15. Tousoulis D, Siasos G, Maniatis K, Oikonomou E, Kioufis S, et al. (2013) Serum osteoprotegerin and osteopontin levels are associated with arterial stiffness and the presence and severity of coronary artery disease. Int J Cardiol 167: 1924-1928.

16. Stepien E, Wypasek E, Stopyra K, Konieczynska M, Przybylo M, et al (2011) Increased levels of bone remodeling biomarkers (osteoprotegerin and osteopontin) in hypertensive individuals. Clin Biochem 44: 826-831.

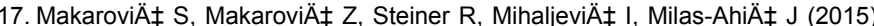
Osteoprotegerin and Vascular Calcification: Clinical and Prognostic Relevance. Coll Antropol 39: 461-468.

18. Kadoglou NP, Gerasimidis T, Golemati S, Kapelouzou A, Karayannacos PE, et al. (2008) The relationship between serum levels of vascular calcification inhibitors and carotid plaque vulnerability. J Vasc Surg 47: 55-62.

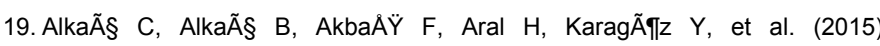
Osteoprotegerin as a marker of atherosclerosis in type 1 and type 2 diabetic patients. Turk J Med Sci 45: 1306-1311.

20. Esteghamati A, Sheikhbahaei S, Hafezi-Nejad N, Mousavizadeh M, Noshad $\mathrm{S}$, et al. (2014) Serum osteoprotegerin in relation to metabolic status, severity and estimated risk of subsequent coronary heart disease. Arch Iran Med 17: $596-601$.

21. Hosbond SE, Diederichsen AC, Saaby L, Rasmussen LM, Lambrechtsen J, et al. (2014) Can osteoprotegerin be used to identify the presence and severity of coronary artery disease in different clinical settings? Atherosclerosis 236 230-236. 
22. Baud'huin M, Duplomb L, Teletchea S, Lamoureux F, Ruiz-Velasco C, et al. (2013) Osteoprotegerin: multiple partners for multiple functions. Cytokine Growth Factor Rev 24: 401-409.

23. Sasso GR, Florencio-Silva R, Simões RS, Baracat MC, Soares Júnior JM, et al. (2015) Elevated serum osteoprotegerin levels in women: friend or foe? Rev Assoc Med Bras 61: 524-529.

24. Xu T, Wang L, Tao Y, Ji Y, Deng F, et al. (2016) The Function of Naringin in Inducing Secretion of Osteoprotegerin and Inhibiting Formation of Osteoclasts. Evid Based Complement Alternat Med 2016: 8981650.

25. Wanby P, Nobin R, Von SP, Brudin L, Carlsson M (2016) Serum levels of the bone turnover markers dickkopf-1, sclerostin, osteoprotegerin, osteopontin, osteocalcin and 25-hydroxyvitamin $\mathrm{D}$ in Swedish geriatric patients aged 75 years or older with a fresh hip fracture and in healthy controls. J Endocrinol Invest .

26. Sims NA, Gooi JH (2008) Bone remodeling: Multiple cellular interactions required for coupling of bone formation and resorption. Semin Cell Dev Bio 19: $444-451$

27. Olesen P, Ledet T, Rasmussen LM (2005) Arterial osteoprotegerin: increased amounts in diabetes and modifiable synthesis from vascular smooth muscle cells by insulin and TNF-alpha. Diabetologia 48: 561-568

28. Rozental TD, Herder LM, Walley KC, Zurakowski D, Coyle K, et al. (2015) 25-Hydroxyvitamin-D and Bone Turnover Marker Levels in Patients with Distal Radial Fracture. J Bone Joint Surg Am 97: 1685-1693.

29. Kimberley FC, Screaton GR (2004) Following a TRAIL: update on a ligand and its five receptors. Cell Res 14: 359-372.

30. Maser RE, Lenhard MJ, Pohlig RT, Balagopal PB (2015) Osteopontin and osteoprotegerin levels in type 2 diabetes and their association with cardiovascular autonomic function. J Diabetes Complications 30: 507-510.

31. Bernardi S, Fabris B, Thomas M, Toffoli B, Tikellis C, et al. (2014) Osteoprotegerin increases in metabolic syndrome and promotes adipose tissue proinflammatory changes. Mol Cell Endocrinol 394: 13-20.

32. Suliburska J, Bogdanski P, Gajewska E, Kalmus G, Sobieska M, et al. (2013) The association of insulin resistance with serum osteoprotegerin in obese adolescents. J Physiol Biochem 69: 847-853

33. Toffoli B, Bernardi S, Candido R, Sabato N, Carretta R, et al. (2011) Osteoprotegerin induces morphological and functional alterations in mouse pancreatic islets. Mol Cell Endocrinol 331: 136-142.

34. WÄ ${ }^{T M}$ drychowicz A, Stec M, Sztefko K, Starzyk JB (2014) Associations between bone, fat tissue and metabolic control in children and adolescents with type 1 diabetes mellitus. Exp Clin Endocrinol Diabetes 122: 491-495.

35. Cunha JS, Ferreira VM, Maquigussa E, Naves MA, Boim MA (2014) Effects of high glucose and high insulin concentrations on osteoblast function in vitro. Cell Tissue Res 358: 249-256.

36. Bumdelger B, Kokubo H, Kamata R, Fujii M, Yoshimura K, et al. (2016) Osteoprotegerin Prevents Development of Abdominal Aortic Aneurysms. PLoS One 11: e0147088.

37. Ovchinnikova O, Gylfe A, Bailey L, Nordström A, Rudling M, et al. (2009) Osteoprotegerin promotes fibrous cap formation in atherosclerotic lesions of ApoE-deficient mice-brief report. Arterioscler Thromb Vasc Biol 29: 1478-1480.

38. Lee CJ, Wang JH, Chen ML, Yang CF, Chen YC, et al. (2015) Serum osteoprotegerin is associated with arterial stiffness assessed according to the cardio-ankle vascular index in hypertensive patients. J Atheroscler Thromb 22: 304-312.

39. Albu A, Bondor Cl, CrÄfciun AM, Fodor D (2014) Circulating osteoprotegerin and asymptomatic carotid atherosclerosis in postmenopausal non diabetic women. Adv Med Sci 59: 293-298.

40. Hosbond SE, Diederichsen AC, Saaby L, Rasmussen LM, Lambrechtsen J, et al. (2014) Can osteoprotegerin be used to identify the presence and severity of coronary artery disease in different clinical settings? Atherosclerosis 236: 230-236.

41. Berezin A, Kremzer A, Berezina T, Martovitskaya Y, Gromenko O (2016) Relation of osteoprotegerin level and numerous of circulating progenitor mononuclears in patients with metabolic syndrome. Biomedical Research and Therapy 3: 501-513.

42. Berezin AE, Kremzer AA, Martovitskaya YV, Samura TA, Berezina TA, et al. (2015) The utility of biomarker risk prediction score in patients with chronic heart failure. Int J Clin Exp Med 8: 18255-18264.
43. Jono S, Otsuki S, Higashikuni Y, Shioi A, Mori K, et al. (2010) Serum osteoprotegerin levels and long-term prognosis in subjects with stable coronary artery disease. J Thromb Haemost 8: 1170-1175.

44. Tavintharan S, Pek LT, Liu JJ, Ng XW, Yeoh LY, et al. (2014) Osteoprotegerin is independently associated with metabolic syndrome and microvascula complications in type 2 diabetes mellitus. Diab Vasc Dis Res 11: 359-362.

45. Chang YH, Lin KD, He SR, Hsieh MC, Hsiao JY, et al. (2011) Serum osteoprotegerin and tumor necrosis factor related apoptosis inducing-ligand (TRAIL) are elevated in type 2 diabetic patients with albuminuria and serum osteoprotegerin is independently associated with the severity of diabetic nephropathy. Metabolism 60: 1064-1069.

46. Evrard S, Delanaye P, Kamel S, Cristol JP, Cavalier E; SFBC / SN joined working group on vascular calcifications (2015) Vascular calcification: from pathophysiology to biomarkers. Clin Chim Acta 438: 401-414.

47. Pepene CE, Ilie IR, Marian I, Duncea I (2011) Circulating osteoprotegerin and soluble receptor activator of nuclear factor? B ligand in polycystic ovary syndrome: relationships to insulin resistance and endothelial dysfunction. Eur J Endocrinol 164: 61-68.

48. Hao Y, Tsuruda T, Sekita-Hatakeyama Y, Kurogi S, Kubo K, et al. (2016) Cardiac hypertrophy is exacerbated in aged mice lacking the osteoprotegerin gene. Cardiovasc Res 110: 62-72.

49. Moran CS, Jose RJ, Biros E, Golledge J (2014) Osteoprotegerin Deficiency Limits Angiotensin II-Induced Aortic Dilatation and Rupture in the Apolipoprotein E-Knockout Mouse. Arterioscler Thromb Vasc Biol 34: 2609-2616.

50. Soysal-Atile N, Guldiken S, Sipahi T, Yukcu F, Ekiz-Bilir B, et al. (2015) Relationship Between an Osteoprotegerin Gene Polymorphism and Diabetic Vascular Complications. Clin Lab 61: 595-601.

51. Duan P, Wang ZM, Liu J, Wang LN, Yang Z, et al. (2015) Association of gene polymorphisms in RANKL / RANK / OPG system with hypertension and blood pressure in Chinese women. J Hum Hypertens 29: 749-753.

52. Biscetti F, Porreca CF, Bertucci F, Straface G, Santoliquido A, et al. (2014) TNFRSF11B gene polymorphisms increased risk of peripheral arteria occlusive disease and critical limb ischemia in patients with type 2 diabetes. Acta Diabetol 51: 1025-1032.

53. MankoÄ RamuÅ $\mathrm{S}, \mathrm{Kum} \AA_{j}$ e T, GloboÄ nik PetroviÄ M, PetroviÄ D, Cilen $\AA_{j}$ ek (2013) SNP rs2073618 of the osteoprotegerin gene is associated with diabetic retinopathy in Slovenian patients with type 2 diabetes. Biomed Res Int 2013 : 364073.

54. Olesen P, Nguyen K, Wogensen L, Ledet T, Rasmussen LM (2007) Calcification of human vascular smooth muscle cells: associations with osteoprotegerin expression and acceleration by high-dose insulin. Am J Physiol Heart Circ Physiol 292: 1058-1064.

55. Jørgensen GM, Vind B, Nybo M, Rasmussen LM, Højlund K (2009) Acute hyperinsulinemia decreases plasma osteoprotegerin with diminished effect in type 2 diabetes and obesity. Eur J Endocrinol 161: 95-101.

56. Nuche-Berenguer B, Portal-Núñez S, Moreno P, González N, Acitores A, et al. (2010) Presence of a functional receptor for GLP-1 in osteoblastic cells, independent of the cAMP-linked GLP-1 receptor. J Cell Physiol 225: 585-592.

57. Nuche-Berenguer B, Moreno P, Esbrit P, Dapía S, Caeiro JR, et al. (2009) Effect of GLP-1 treatment on bone turnover in normal, type 2 diabetic, and insulin-resistant states. Calcif Tissue Int 84: 453-461.

58. Davenport C, Mahmood WA, Forde H, Ashley DT, Agha A, et al. (2015) The effects of insulin and liraglutide on osteoprotegerin and vascular calcification in vitro and in patients with type 2 diabetes. Eur J Endocrinol 173: 53-61.

59. Nuche-Berenguer B, Lozano D, Gutiérrez-Rojas I, Moreno P, Mariñoso ML, et al. (2011) GLP-1 and exendin-4 can reverse hyperlipidic-related osteopenia. J Endocrinol 209: 203-210.

60. Nybo M, Preil SR, Juhl HF, Olesen M, Yderstraede K, et al. (2011) Rosiglitazon decreases plasma levels of osteoprotegerin in a randomized clinical trial with type 2 diabetes patients. Basic Clin Pharmacol Toxicol 109: 481-485.

61. Esteghamati A, Azizi R, Ebadi M, Noshad S, Mousavizadeh M, et al. (2015) The comparative effect of pioglitazone and metformin on serum osteoprotegerin adiponectin and intercellular adhesion molecule concentrations in patients with newly diagnosed type 2 diabetes: a randomized clinical trial. Exp Clin Endocrinol Diabetes 123: 289-295.

62. Park JS1, Cho MH, Nam JS, Yoo JS, Ahn CW, et al. (2011) Effect of pioglitazone on serum concentrations of osteoprotegerin in patients with type 2 diabetes mellitus. Eur J Endocrinol 164: 69-74. 
Citation: Berezin AE (2016) Can Osteoprotegerin be a Target of Therapy in Type 2 Diabetes Mellitus? Metabolomics 6: 172. doi:10.4172/21530769.1000172

63. Koufany M, Chappard D, Netter P, Bastien C, Weryha G et al. (2013) The peroxisome proliferator-activated receptor? agonist pioglitazone preserves bone microarchitecture in experimental arthritis by reducing the interleukin-17dependent osteoclastogenic pathway. Arthritis Rheum 65: 3084-3095.

64. Shao X, Cao X, Song G, Zhao Y, Shi B (2014) Metformin rescues the MG63 osteoblasts against the effect of high glucose on proliferation. J Diabetes Res 2014: 453940

65. Liu L, Zhang C, Hu Y, Peng B (2012) Protective effect of metformin on periapical lesions in rats by decreasing the ratio of receptor activator of nuclear factor kappa B ligand/osteoprotegerin. J Endod 38: 943-947.

66. Mai QG, Zhang ZM, Xu S, Lu M, Zhou RP, et al. (2011) Metformin stimulates osteoprotegerin and reduces RANKL expression in osteoblasts and ovariectomized rats. J Cell Biochem 112: 2902-2909.

67. Pearson $E$ (2016) Personalized medicine in diabetes: the role of 'omics' and biomarkers. Diabet Med

68. Lenglet S, Quercioli A, Fabre M, Galan K, Pelli G, et al. (2014) Statin treatment is associated with reduction in serum levels of receptor activator of NF?B ligand and neutrophil activation in patients with severe carotid stenosis. Mediators Inflamm 720987
69. Rattazzi M, Faggin E, Buso R, Di Virgilio R, Puato M, et al. (2016) Atorvastatin Reduces Circulating Osteoprogenitor Cells and T-Cell RANKL Expression in Osteoporotic Women: Implications for the Bone-Vascular Axis. Cardiovasc Ther 34: 13-20.

70. Davenport C, Ashley DT, O'Sullivan EP, McHenry CM, Agha A, et al. (2015) The Effects of Atorvastatin on Arterial Stiffness in Male Patients with Type 2 Diabetes. J Diabetes Res 2015: 846807.

71. Hegazy SK, El-Ghany SE, El-Hefnawy ME (2016) A Clinical Study Evaluating The Effects of Fluvastatin on Serum Osteoprotegerin Levels in Rheumatoid Arthritis Patients. J Clin Pharmacol .

72. Steinmetz M, Pelster B, Lucanus E, Arnal JF, Nickenig G, et al. (2013) Atorvastatin-induced increase in progenitor cell levels is rather caused by enhanced receptor activator of NF-kappaB ligand (RANKL) cell proliferation than by bone marrow mobilization. J Mol Cell Cardiol 57: 32-42.

73. Berezin AE (2016) Metabolic memory phenomenon in diabetes mellitus: achieving and perspectives. Diabetes and Metabolic Syndrome: Clinical Research and Reviews. 